\title{
THE CONTRIBUTION OF AZOLLA AND UREA IN LOWLAND RICE GROWTH PRODUCTION FOR THREE CONSECUTIVE SEASONS
}

\author{
E.L. Sisworo, H. Rasjid, Haryanto and Idawati \\ Centre For the Application of Isotopes and Radiation \\ National Nuclear Energy Agency (BATAN) \\ Cinere Pasar Jum'at PO.Box 7002 JKSKL, Jakarta 12070, Indonesia
}

\begin{abstract}
THE CONTRIBUTION OF AZOLLA AND UREA IN LOWLAND RICE GROWTH PRODUCTION FOR THREE CONSECUTIVE SEASONS. Three field experiments have been carried out in three consecutive seasons namely wet season (120 days), dry season (120 days), wet season (120 days) at Pusakanegara. The purpose of this experiment is to test whether urea combined with Azolla could increase lowland rice production and soil quality. The experimental plots have a size of $20 \mathrm{~m}^{2}$ and in each experimental plot an isotope plot was placed with a size of $1 \mathrm{~m}^{2}$. The isotope plots were used to apply labeled ${ }^{15} \mathrm{~N}$ urea. Treatments conducted were lowland varieties: Atomita I (V1) and IR-64 (V2); several levels of urea and Azolla : Pu1 = urea-tablets + an Azolla cover $($ Azc $)$, Pu2 = urea-tablets + Azolla incorporated (Azi ), Pu3 = urea-prill + Azc, $\mathrm{Pu} 4=$ urea-prill + Azi; seasons : Ss $1=$ wet season, Ss2 = dry season, Ss3 = wet season. The experimental design used was a factorial experiment in a Randomized Block Design, where each treatment was replicated four times. Parameters used were, dry weight of straw $(\mathrm{St})$, grain $(\mathrm{G})$, plant $(\mathrm{P} 1=\mathrm{St}+\mathrm{G})$ in $\mathrm{kg} / \mathrm{ha}$; $\mathrm{N}$-total percentage (\% N-to) of St and G, percentage N-derived from urea + Az (\% N-Pu) of St and G; percentage N-derived from soil (\% N-S) of St and G; uptake of N-Pu and N-S in St, G and P1. Some results of these experiment were, $\mathrm{N}-\mathrm{Pu}$ play a less important role in growth of lowland crop expressed in several parameters compared to $\mathrm{N}$-soil. The form of $\mathrm{N}$-urea in tablets are superior to that the form of urea in prills. For the last product of lowland rice which is grain obviously V1 (Atomita-1) is better than V2 (IR-64) expressed in t/ha. The progress of seasons showed clearly that there is an $\mathrm{N}$ accumulation which might be the increase of soil organic matter (SOM) and that means there is an increase in soil quality in the view point of $\mathrm{N}$.
\end{abstract}

Key words: Azolla, Urea, Lowland rice

\section{INTRODUCTION}

Soil is a source for natural resources which is very important for the life of mankind. Soil is the base for fulfilling the physical necessity of man such as, food, clothing, and other non physical needs. Due to soil's wide and large fungsional purpos it is so frequently exploited exceeding its capability, and the main result is damage of its physical and chemical properties [1,2,3].

In Indonesia the most common soil damage is the diminishing of the soil organic matter (SOM) content which will cause the diminishing of soil capability for plant growth and productivity. This is in line with VERSTRATE [4] who stated that the OM rate of decomposition in wet tropical area is much faster compared to sub-tropical areas and this will result that in wet tropical areas such as Indonesia OM will disappear fast with detrimental results when not inhibited. 
SOM has a vital role in the capability to support plant growth. Further SOM will influence the physical and biological properties of the soil. According to STEVENSON [5], SOM is all organic matter (OM) found in soil, including mulch, light weight $\mathrm{OM}$, biomass of soil microorganism, OM dissolved in water and stable OM known under the name of humus. The soil damage due to diminishing SOM, could destroy the physical, biological properties of soil, so it could loss the capability to support plant production.

To improve the three soil properties mentioned simultaneously the best alternative is to apply OM and anorganic fertilizer [2]. Green manure is one of an OM form and could increase SOM. Because of their high $\mathrm{N}_{2}$-fixing ability in standing water, Azolla is considered as a potential green manure.

In this paper, the use of Azolla as a green manure combined with urea done in three consequtive seasons applied to lowland rice to improve growth and production of rice and to improve soil quality is reported.

\section{EXPERIMENTAL METHOD}

\section{Plant Materials}

Plant material used were two lowland rice varietirs namely, V1: Atomita-1 and V2 : IR-64. Three weeks seedling were transplanted into the field and harvested at grain maturity and were done at three consecutive seasons Ss1 (wet season) - Ss2 (dry season) - Ss3 (wet season). Each season lasted around 120 days.

\section{Location and Experiment Plots}

Location of the experiment is in Pusakanegara at the experimental Station of Department of Agriculture. Each experiment plot consisted of two parts, the large part has a size of $20 \mathrm{~m}^{2}$ and is named yield plot and each yield plot has a plot size of $1 \mathrm{~m}^{2}$ and is called isotope plot. In the isotope plot, the ${ }^{15} \mathrm{~N}$ compound is applied, in this case it was ${ }^{15} \mathrm{~N}$ labeled urea with a $10 \%$ abundance.

\section{Treatments Apllied Experimental Design and Parameters Observed}

Treatment applied in this experiment are tabulated as follow:

\begin{tabular}{|cc|c|c|c|c|}
\hline & Pul & Pu2 & Pu3 & Pu4 \\
\hline V1 & Ss1 & Azi + UT & Azc + UT & Azi + UP & Azc + UP \\
\hline & Ss2 & Azi + UT & Azc + UT & Azi + UP & Azc + UP \\
\hline & Ss3 & Azi + UT & Azc + UT & Azi + UP & Azc + UP \\
\hline V2 & Ss1 & Azi + UT & Azc + UT & Azi + UP & Azc + UP \\
\hline & Ss2 & Azi + UT & Azc + UT & Azi + UP & Azc + UP \\
\hline & Ss3 & Azi + UT & Azc + UT & Azi + UP & Azc + UP \\
\hline
\end{tabular}

Azi : Azolla incorporated into the soil. Azolla was grown 3 weeks before soil preparation for transplanting, which was about three weeks, at this time it has covered the whole water surface, when incorporated it was at rate of $2 \mathrm{t} / \mathrm{ha}$.

Azc : Azolla floated on water surface, Azolla as in Azi was grown for three weeks, and after having covered the surface of the water, transplanting was done and the Azolla cover was left covering the water surface. 
The experimental design used was a factorial experiment involving a randomized block design where each treatment was replicated four times. In this factorial experiment, the treatment were season with three levels ( $\mathrm{Ss} 1, \mathrm{Ss} 2$, and $\mathrm{Ss} 3$ ) ; lowland rice varieties (V1, V2), where V1 is Atomita-1 and V2 is IR-64; N-fertilizer with four levels (Pul, Pu2, Pu3, and Pu4), and its interactions as will be shown in all the following tables. Parameters observed were dry weight of straw (St), grain $(\mathrm{G})$, and plants $(\mathrm{P} 1=\mathrm{St}+\mathrm{G})(\mathrm{kg} / \mathrm{ha}) ; \mathrm{N}$-total percentage $(\% \mathrm{~N}$-to) of St and G; percentage of $\mathrm{N}$-derived from urea $(\% \mathrm{~N}-\mathrm{Pu})$ of $\mathrm{St}$ and $\mathrm{G}$; percentage of $\mathrm{N}$-derived from soil (\% N-S) of St and G; uptake of N-Pu and N-S in St, G, and P1 (kg N/ha). The $\% \mathrm{~N}-\mathrm{Pu}$ and $\% \mathrm{~N}-\mathrm{S}$ for St and G are taken from the isotope plots. Here the $\mathrm{N}$ contributed by Azolla either by Azi oir Azc is considered as N-soil because it would be mineralized and assumed contributed to the $\mathrm{N}$-soil.

\section{RESULTS AND DISCUSSION}

\section{Dry Weight}

In Table 1, data presented are for dry weight of straw (St), grain $(\mathrm{G})$, and plant $(\mathrm{P} 1 \mathrm{St}+\mathrm{G})$. The ANOVA showed that, for dry weight of St, G, and P1, only the total treatments and the single treatment Ss have highly significant difference, while the other treatments showed no difference among them, except for St (Pu x V x S) and P1 (V). From the ANOV A, Pu treatment, whether urea in the form of tablets added with Azolla incorporated (Azi) or as a cover (Azc), these are Pul and Pu2, and prill urea with Azi or Ac (Pu3 and Pu4) did not influence the dry weight of all the parameters observed. Based on this it could be assumed that the form of urea, either tablets or prill added with Azi or Azc has equal influences on dry weight, of St, G, P1. It could be speculated that the soil has already enough nitrogen (N) from SOM so no response was given by the lowland crop on $\mathrm{N}$ addition of outside sources.

Perusal of the ANOVA showed that no difference in dry weight was found between V1 and V2 in St and G, but difference was found in P1 between V1 and V2, where V1 gave higher dry weight than V2. When looking at St and G dry weight of V1 consistently showed higher values than that of V2, although not significantly different. Based on the dry weight of St, G, and P1 that there could be different between varieties in their production, in this case between V1 and V2. This should be taken into consideration when high production was sought for. 
Table 1. Dry weight of straw, grain, and plants of lowland rice with several $\mathrm{N}$-fertilizer levels at three consecutive

\begin{tabular}{|c|c|c|c|c|c|c|c|c|c|c|c|c|c|c|c|}
\hline & \multicolumn{5}{|c|}{ Siraw (Sa)-1hu } & \multicolumn{5}{|c|}{$\operatorname{Grgin}(G)-1$ ha } & \multicolumn{5}{|c|}{ Pland } \\
\hline & N.PeII & N.P.2 & N.Pus & NPuA & & NaPel & $\mathrm{N}+\mathrm{h}+2$ & N.Fus & Nhot & & N.Pul & $N \rightarrow 2$ & $\mathrm{~N}-\mathrm{P}=3$ & NPOA & \\
\hline \multicolumn{16}{|l|}{ Bo-PaxVnst } \\
\hline $\begin{aligned} \text { VI } 851 \\
802\end{aligned}$ & $\frac{3.005}{4475}$ & $\frac{3.354}{42194}$ & $\frac{4000}{4104}$ & $\frac{3.84}{4(x)}$ & & $\frac{5.526}{7100}$ & $\frac{5353}{6.138}$ & $\frac{3.45 x}{6.463}$ & $\frac{3501}{6300}$ & & $\frac{9011}{115}$ & $\frac{8.717}{104 \times 2}$ & 9.513 & $\frac{9603}{6997}$ & \\
\hline$\$ 2.3$ & 4004 & 5200 & 40,23 & 4.732 & & 5006 & 6.617 & 5.443 & 6.147 & & 11.015 & $11048 \pi$ & $\frac{10350}{10395}$ & $\frac{10819}{10314}$ & \\
\hline 7289 & 3716 & 352 & 3.606 & 3.215 & & 5850 & 5,600 & 5.109 & 5.303 & & 9516 & 9212 & 8.706 & 9017 & \\
\hline Sn2 & 464 & 4219 & 4.203 & 43212 & & 6075 & 6753 & 5,400 & 6000 & & 10.57 & 10544 & 9.836 & 10322 & \\
\hline 8.3 & 4000 & 5108 & 4553 & 4.316 & & 5950 & 5.723 & 5.494 & 5.691 & & 10.40 & 10529 & 10047 & $10 \times 97$ & \\
\hline Rery & $43 \pi$ & 4.303 & 42215 & 4266 & & 6001 & 5976 & 355 & 5933 & & 10.455 & $102 \mathrm{~m} 7$ & 9836 & 102217 & \\
\hline Rothary & & & & & $\operatorname{Rog} \theta$ & & & & & $80 . \mathrm{V}$ & & & & & Eon- $\mathrm{V}$ \\
\hline $\mathrm{vI}$ & 4308 & 4.323 & 4345 & 4.416 & $4(5)$ & 6177 & 6090 & $5 \times 13$ & 6 काas! & 6004 & 10955 & 1039 & 10.142 & 10459 & 10394 \\
\hline$\sqrt{2}$ & 4416 & 4283 & $4|2|$ & 4117 & $4 \times 2$ & 505 & 5.909 & 5332 & 5.825 & 3.534 & 10345 & 10.125 & 9529 & 9.945 & 10004 \\
\hline \multicolumn{16}{|l|}{ Po-hasis } \\
\hline $5 \mathrm{~s}$ & 3.616 & 3,438 & 3.813 & 3534 & 350 & 5.605 & 5.527 & 5200 & $5 \mathrm{sm}$ & 8573 & 92223 & 8565 & 9111 & 9.336 & 9.131 \\
\hline 50 & 454 & 4297 & 4153 & 4491 & 4371 & 6588 & 6.231 & 5931 & 6.150 & 625 & 11.213 & 10313 & 10100 & 10.670 & 10699 \\
\hline 823 & 4.956 & 5.134 & 479 & $47 \pi 4$ & 4916 & 5,203 & 6.170 & $\operatorname{sen} \alpha$ & 5906 & $\sin \theta$ & 10.59 & 11.353 & 10206 & 10.655 & 10.186 \\
\hline$R=\sqrt{x} 3_{1}$ & SEI & $\sec$ & sis & & & Sst & 502 & 53 & & & S51 & $\sin 2$ & 553 & & \\
\hline & 3693 & 4398 & 4004 & & & 5.545 & 6.500 & 6027 & & & 922 & 10 का & 10 का & & \\
\hline$\sqrt{2}$ & 3515 & 4024 & $4 \times 6$ & & & 5.590 & 3986 & 5.12 & & & 9114 & 10317 & 10595 & & \\
\hline & & & & & & & & & & & & & & & \\
\hline \multicolumn{16}{|l|}{ ANOVA } \\
\hline & \multirow{2}{*}{\multicolumn{5}{|c|}{ FCriculaid }} & \multirow{2}{*}{\multicolumn{5}{|c|}{ Fecolctinad }} & & & & \multirow{2}{*}{\multicolumn{2}{|c|}{ f-Thile }} \\
\hline & & & & & & & & & & & & & & & 15 \\
\hline Trealinerts & \multirow{2}{*}{\multicolumn{5}{|c|}{$\frac{6674^{-2}}{0.426}$}} & \multicolumn{5}{|c|}{$1548^{\prime}$} & \multicolumn{3}{|c|}{$4222^{\prime \prime}$} & 1.865 & 2005 \\
\hline$P_{4}$ & \multirow{2}{*}{\multicolumn{5}{|c|}{$\frac{0422^{5}}{12 w^{2}}$}} & \multirow{2}{*}{\multicolumn{5}{|c|}{$\frac{2600^{\circ}}{3197^{2}}$}} & \multirow{2}{*}{\multicolumn{3}{|c|}{$\frac{2.247^{\circ}}{4.887^{7}}$}} & 2743 & 400 \\
\hline$v$ & & & & & & & & & & & & & & $3.5 n 2$ & 7.616 \\
\hline Ss & \multirow{2}{*}{\multicolumn{5}{|c|}{$\frac{663011^{11}}{1050}$}} & \multirow{2}{*}{\multicolumn{5}{|c|}{$\frac{7600 "}{0.658}$}} & \multicolumn{3}{|c|}{$141133^{\prime \prime}$} & 3.133 & 4928 \\
\hline Pay & & & & & & \multirow{2}{*}{\multicolumn{5}{|c|}{$\frac{0.268^{*}}{0.51 T^{*}}$}} & \multicolumn{3}{|c|}{$039=$} & 2.743 & 4.063 \\
\hline Fos: & \multicolumn{5}{|c|}{$1.50 \mathrm{~m}$} & & & & & & \multirow{2}{*}{\multicolumn{3}{|c|}{$\frac{126 r^{2}}{0.751^{2}}$}} & 2.232 & 3.074 \\
\hline Vrit & \multirow{2}{*}{\multicolumn{5}{|c|}{$\frac{0.127^{\prime \prime}}{9.4 .4^{\prime \prime}}$}} & \multirow{2}{*}{\multicolumn{5}{|c|}{$\frac{1.651^{*}}{1.379}$}} & & & & 3.13 & 4.928 \\
\hline Pexvevesis & & & & & & & & & & & & 0365 & & 2.232 & 3.034 \\
\hline cV $(S)$ & & & 107 & \multicolumn{2}{|c|}{ 9.4.4" } & & - & $4 \times 2$ & & & & & 5,5 & & \\
\hline
\end{tabular}

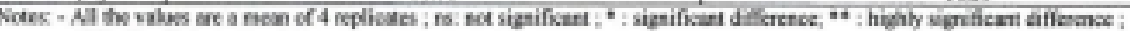

$$
\text { CV : Coefficiente of raiation }
$$


An interesting observation was shown by the treatment of seasons ( $\mathrm{Ss}$ ). For St and P1, the dry weight increase from season to season (Ss1 < Ss2 < Ss3), but not so for G. The highest dry weight was found at Ss2 $(\mathrm{Ss} 1<\mathrm{Ss} 3<\mathrm{Ss} 2)$. It has been mentioned in Method and Materials, that the work at Ss1 and Ss3 were done in the wet season. Apparently in the dry season (Ss2) where light intensity at dry season is much higher then in the wet season (Ss1 and Ss3) and water was enough to be used by the crop, the $\mathrm{CO}_{2}$ fixation and all the metabolism related with it is high resulting in high grain $(\mathrm{G})$ production as found in this work. From all the interaction of two treatments despite no difference was shown, most of the data were in line with the single treatment $\mathrm{V}$. Thus, if dry weight of $\mathrm{V} 1>\mathrm{V} 2$, then the interaction of $\mathrm{V} 1$ with $\mathrm{Pu}$ or Ss will show higher dry weight too over that of the interaction with $\mathrm{V} 2$.

\section{Total-N Percentage $(\% \mathbf{N}$-to)}

In Table 2, the ANOVA showed that, for St and $\mathrm{G}$ differences were found for the total treatments $\left({ }^{* *}\right), \mathrm{V}\left({ }^{* *}\right)$, Ss $\left({ }^{* *}\right)$, VxS $\left({ }^{* *}\right)$. Significant interaction was also found too for $\mathrm{Pu} \times \mathrm{x} \quad \mathrm{V} \times \mathrm{S}^{*}\left(^{*}\right)$. Only the treatments with differences especially for the interactions will be discussed.

Table 2. Total-N percentage (\%N-to) of straw and grain of lowland rice applied with several levels of $\mathrm{N}$-fertilizers at three consecutive seasons.

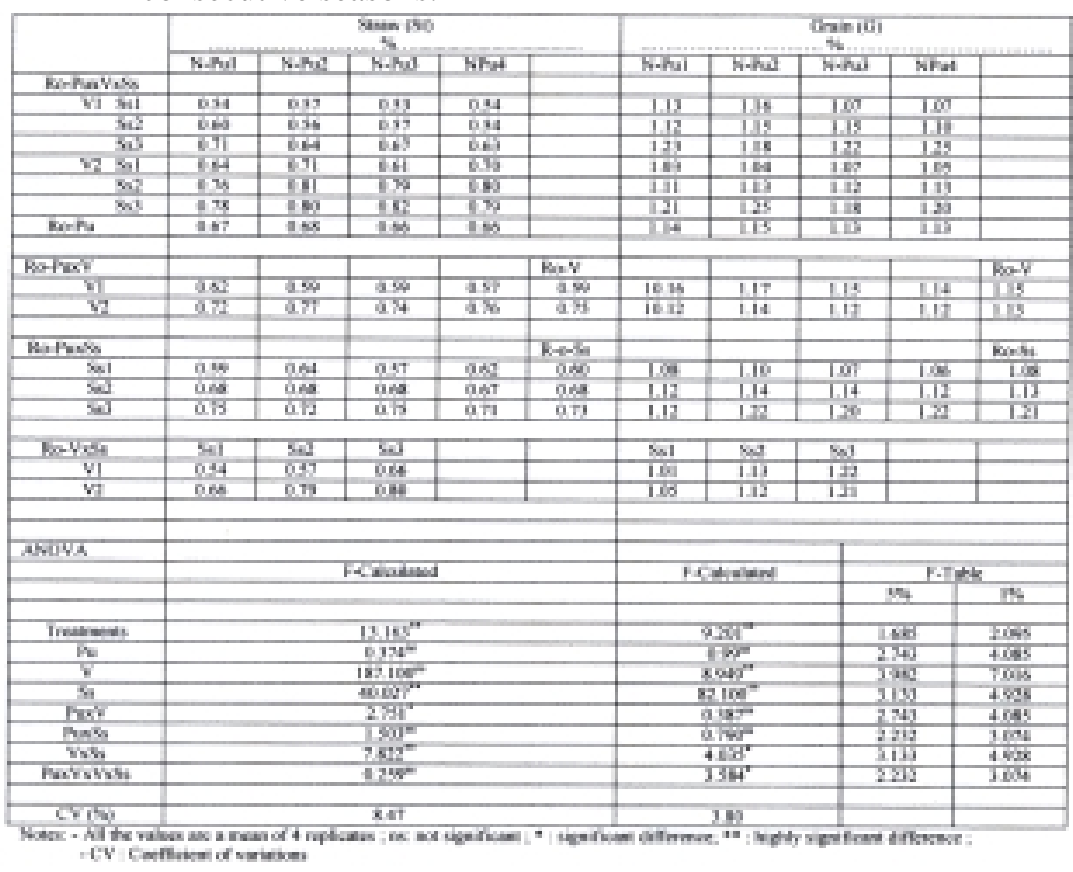


No differences were found for the treatment Pu either in St or G. This could be due to that the potential of the $\% \mathrm{~N}$-to of St (average $0.66 \%$ ) and $\mathrm{G}$ (average $1.13 \%$ ) have been reached in this work. The addition of urea in the form of tablets or prill with Azi and Azc had no influence whatever on the $\% \mathrm{~N}$-to. For the difference between V1 and V2, reverse results were obtained. This reversed results showed that for $\mathrm{St} \% \mathrm{~N}$-to of $\mathrm{V} 1$ $(0.59 \%)<\mathrm{V} 2(0.75 \%)$, but for G \% N-to of V1 $(1.15 \%)>\mathrm{V} 2(1.13 \%)$. This could be due that for $\mathrm{V} 1$, the $\mathrm{N}$ from straw was more efficient distributed to the grains $(\mathrm{G})$ than that of $\mathrm{V} 2$, resulting in higher \% N-to of V1 to that of $\mathrm{V} 2$ for $\mathrm{G}$.

The \% N-to of St and G, for the seasons, showed consistently increase from Ssl to Ss3, [St: Ssl $(0.60 \%<\mathrm{Ss} 2(0.68 \%)<\mathrm{Ss} 3(0.73 \%)$ ]; [G: Ssl $(1.08 \%)<$ Ss2 $(1.13 \%)$, Ss3 $(1.21 \%)$ ]. It might be that this could be due to the increasing $\mathrm{N}$ in the soil with the progress of the seasons, resulting in increasing $\% \mathrm{~N}$-to from season to season. For the interaction $\mathrm{Pu} \times \mathrm{V} \times \mathrm{Ss}$ only $\mathrm{G}$ showed significant difference. In crops where the end production is grain like lowland rice, all the nutrient absorbed including that of $\mathrm{N}$ will be piled up in the grain $(\mathrm{G})$ resulting significant difference for $\mathrm{Pu} \times \mathrm{V}$ x S.

\section{N-Total (N-to) Uptake}

The perusal of the ANOV A in Table 3 showed that significant $\left({ }^{*}\right)$ and highly significant $\left({ }^{* *}\right)$ was found for treatments: St $\left.\left({ }^{* *}\right), \mathrm{G}\left({ }^{* *}\right), \mathrm{P} 1{ }^{* \star}\right)$;

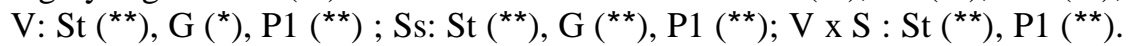
The rest of treatments single or interaction are not significant (ns).

For Pu as in \% N-to, the uptake of N-to (kg N/ha) is not significant among Pu1 to P4. The explanation is in \% $\mathrm{N}$-to, where it might be that the $\mathrm{N}$-soil is already high, so addition of urea in the form of tablets or prill combined with Azi and Azc were not responded by V1 or V2. As known the $\mathrm{N}$-to uptake is the result of dry weight times $\% \mathrm{~N}$ - to. In Table 1 it is shown that there is no significant difference between V1 and V2 for dry weight, but significant differences was found for $\% \mathrm{~N}$-to. Apparently $\% \mathrm{~N}$-to has quite an influence on the $\mathrm{N}$-to uptake by showing significant difference between $\mathrm{V} 1$ and $\mathrm{V} 2$ as was shown too by $\% \mathrm{~N}$-to.

Like in $\% \mathrm{~N}$-to for $\mathrm{N}$-to uptake in $\mathrm{St}: \mathrm{V} 1<\mathrm{V} 2, \mathrm{G}: \mathrm{V} 1>\mathrm{V} 2$, $\mathrm{P} 1$ : V1 < V2. For lowland rice or other seed crops, the most important end product is the grain production. In this work it is gained that for dry weight $\mathrm{G}: \mathrm{V} 1>\mathrm{V} 2$ (ns), for \% $\mathrm{N}$-to : V1 > V2 $\left(^{* *}\right)$,for total N-uptake V1 > V2 $\left(^{*}\right)$, so although for other parameters (St and P1) where V1 $<$ V2, but when it come to choosing which variety should be recommended then with great certainty V1 should be recommended. Data shown by Ss for N-to uptake showed results in line with \% N-to for all the parameters observed (St, G, P1) there is a consistently increase from Ssl to Ss3. This could be explained as before for \% N-to. Obviously the $\mathrm{N}$-soil has been built up from S1 to S3. This made it possible for the crop to take up increasing $\mathrm{N}$ with the progress of 
seasons. It could be speculated that there could be an increase of SOM (Soil Organic Matter) with time and this is the main reason why there is an increase of $\mathrm{N}$.

\section{Percentage N-Derived From Fertilizer (\% N-Pu) and N-Derived From Soil $(\% \mathrm{~N}$-soil)}

Data in Table 4 showed that, differences $(*)$, highly differences $(* *)$ and non significant (ns) differences were found for:

- \% N-PU : total treatments: St $\left({ }^{* *}\right), \mathrm{G}\left({ }^{* *}\right) ; \mathrm{Pu}: \mathrm{St}\left({ }^{* *}\right), \mathrm{G}\left({ }^{* *}\right)$; Ss : St $\left({ }^{* *}\right), \mathrm{G}\left({ }^{* *}\right) ; \mathrm{Pu} \times \mathrm{V}: \mathrm{St}\left({ }^{* *}\right), \mathrm{G}(\mathrm{ns}) ; \mathrm{Pu} \times \mathrm{Ss}: \mathrm{St}\left({ }^{* \star}\right), \mathrm{G}(\mathrm{ns})$

- \% N-soil : total treatments: St $\left({ }^{* *}\right), \mathrm{G}\left({ }^{* *}\right)$; Pu: St $\left({ }^{* *}\right), \mathrm{G}\left({ }^{* *}\right)$; Ss : St $\left({ }^{* *}\right), \mathrm{G}\left({ }^{* *}\right) ; \mathrm{Pu} x \mathrm{~V}: \mathrm{St}\left({ }^{* *}\right), \mathrm{G}(\mathrm{ns}) ; \mathrm{Pu} \times \mathrm{Ss}: \mathrm{St}\left({ }^{* \star}\right), \mathrm{G}(\mathrm{ns})$

For the rest of the treatments $\mathrm{V} \times \mathrm{Ss}$ and $\mathrm{Pu} \times \mathrm{V} \times \mathrm{Ss}$ no significant differences (ns) were found both for $\mathrm{St}$ and $\mathrm{G}$. It was found for $\mathrm{Pu}$ (Table 1,2, 3) all the three parameters: dry weight $(\mathrm{kg} / \mathrm{ha}), \% \mathrm{~N}$-to, and $\mathrm{N}$-to uptake ( $\mathrm{kg} \mathrm{N} / \mathrm{ha}$ ), no difference were found for all of them. It could be assumed that for all the data presented in the previous tables the $\mathrm{N}$ faced by the lowland crop was a total of $\mathrm{N}$ : $\mathrm{N}$-fertilizer $+\mathrm{N}$-soil. Apparently the total-N available have the about same quantity, making the crops were able to take up $\mathrm{N}$ in equal amounts. This resulted in no significant differences were found for the parameters observed. While when looking at N-Pu and N-soil as separated $\mathrm{N}$-sources as shown in Table 4, interesting facts occurred. Obviously the \% N-Pu of urea in the form of tablets combined with Azi and Azc (Pul and Pu2) gave higher results than that of urea prill with Azi and Azc. This was true for St as well as G. For the \% N-soil, the reverse of that of $\mathrm{N}-\mathrm{Pu}$ was observed, which is when $\% \mathrm{~N}-\mathrm{Pu}$ is high or low, then the $\% \mathrm{~N}-\mathrm{S}$ would be the reverse. This data supported the data found previously in Tables 1, 2, 3 where no significant differences were found for $\mathrm{N}-\mathrm{Pu}$ and $\mathrm{N}$-soil, where low $\mathrm{N}-\mathrm{Pu}$ will be covered by high $\mathrm{N}$-soil and the reverse. The non significant difference of $\% \mathrm{~N}-\mathrm{Pu}$ and $\% \mathrm{~N}$-soil between V1 and V2 for $\mathrm{St}$ and $\mathrm{G}$, showed that the varieties used gave equal responses to the $\mathrm{N}$-sources (Pu1, Pu2, Pu3, Pu4).

Another interesting data for $\% \mathrm{~N}-\mathrm{Pu}$ and $\% \mathrm{~N}$-soil for Ss in St and G. It is shown that with the passing of seasons, the \% N-Pu decreased significantly, on the other hand the $\% \mathrm{~N}$-soil increased. This could be due to the built up of the N-soil especially the SOM as a source of N. For the interaction of $\mathrm{Pu} \times \mathrm{V}$ and $\mathrm{Pu} \times \mathrm{S}$ only for $\mathrm{St}$ the $\% \mathrm{~N}-\mathrm{Pu}$ and $\% \mathrm{~N}$-soil showed significant difference but not for G. It seems that an equal distribution was carried out from St to $G$, resulting in non significant differences in $\mathrm{G}$ for $\% \mathrm{~N}-\mathrm{Pu}$ and \% $\mathrm{N}$-soil. More detail discussion will be forwarded for the next Tables which is N-uptake ( $\mathrm{kg} \mathrm{N} / \mathrm{ha}$ ). 
N Table 3. N-total uptake of straw, grain, and plants of lowland rice with several N-fertilizer levels at three consecutive seasons.

\begin{tabular}{|c|c|c|c|c|c|c|c|c|c|c|c|c|c|c|c|}
\hline & \multicolumn{5}{|c|}{$\operatorname{sen}(9)-1$ he } & \multicolumn{5}{|c|}{$\operatorname{Grain}(0)-1)$} & \multicolumn{5}{|c|}{ Finateri)-bia } \\
\hline & Nayl & N:Au2 & NAth & \multicolumn{7}{|c|}{ ko-fayes } & Netral & $N-72$ & $N \cdot n=2$ & SFut & \\
\hline VI $S E 1$ & IIल & $18 \mathrm{cos}$ & 21.20 & 21.24 & & 6201 & 6217 & 800 & 6238 & & 800 & 81.14 & 8160 & 32.22 & \\
\hline 50 & $25 \mathrm{~m}$ & 2477 & 733 & 2526 & & 7985 & 2056 & 2064 & o. 115 & & 10651 & 94.82 & 0.17 & 94.4 & \\
\hline 563 & 3532 & 3335 & 3831 & 36.20 & & 72.77 & 7320 & 67.31 & $7 \pi 73$ & & $\operatorname{lox} 10$ & III.195 & का 16 & 10741 & \\
\hline $\mathrm{V} 2 \$ 1$ & 2353 & $25 \pi$ & 21.5 & 21.2 & & $59 . \mathrm{mo}$ & 520 & 3427 & 61.55 & & 1219 & 87.99 & 7862 & 500 & \\
\hline 50 & 35.10 & 표드 & 3317 & $34 \pi$ & & 502 & 7114 & 60s & 67.95 & & 10266 & 10560 & $93 \times 2$ & 10035 & \\
\hline 803 & $39 m$ & माल & 3628 & 3793 & & 2338 & 7307 & 67.07 & 67.50 & & $1129 \pi$ & 115.60 & 1050 & 10402 & \\
\hline$R \in P Q$ & 2976 & 290 & 28.18 & 21.82 & & कास & 800 & 625 & 67.45 & & 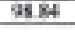 & क.1x & 91.71 & 9613 & \\
\hline Rothas & & & & & Rat $-V$ & & & & & $R=V$ & & & & & $\log V$ \\
\hline$v_{1}$ & 3697 & 853 & 2599 & $25 \pi 3$ & 2606 & 7254 & Tuा & 6694 & $6 . .22$ & His5 & 2853 & 39.84 & कूजा & 0.17 & 9591 \\
\hline$V_{2}$ & 3234 & 3285 & 3.25 & 37.85 & 3218 & 67.01 & 67.75 & 50.67 & 59.53 & 65274 & 9214 & $102 \pi$ & 9091 & 9745 & 9781 \\
\hline Ba-fass & & & & & $50-5 s$ & & & & & $80-55$ & & & & & 6.55 \\
\hline क्षा & 2123 & 22.37 & 214 & 2233 & 21.87 & 6093 & $60(0)$ & 5639 & का. & 935 & 81.59 & 346 & 7731 & 8.31 & $\frac{10214}{x 2}$ \\
\hline 862 & 308 & 2900 & 2323 & 2045 & 245 & 73.72 & 7035 & 67805 & 6153 & 70.10 & 1045 & काज & son & कर 31 & 9972 \\
\hline 5 & 37.16 & 37.65 & $34 \pi$ & 3्र.13 & 359 & 73.11 & $73 . \mathrm{GH}$ & 5772 & 7217 & $72 \pi$ & 1100 & 11323 & 101.33 & 10575 & 107,2 \\
\hline Rerkgit & 851 & 812 & 853 & & & 351 & का & 83 & & & 31 & 59 & का & & \\
\hline vi & 2009 & 2487 & 3318 & & & 6134 & 7355 & 7377 & & & $81+4$ & प्रा4 & $10 \times 52$ & & \\
\hline $\mathrm{V}_{2}$ & 26.65 & 34.11 & 38 & & & $9 \times 45$ & $8 \times 5$ & 7013 & & & 805 & $10 \%$ & 10873 & & \\
\hline & & & & & & & & & & & & & & & \\
\hline \multicolumn{16}{|l|}{ ANOVA } \\
\hline & \multirow{2}{*}{\multicolumn{5}{|c|}{ Fencultad }} & \multirow{2}{*}{\multicolumn{5}{|c|}{ Frakulned }} & & & & \multicolumn{2}{|c|}{ Firolde } \\
\hline & & & & & & & & & & & & & & $3 \%$ & is \\
\hline Treamens & \multirow{2}{*}{\multicolumn{5}{|c|}{$\frac{12.27^{2}}{100^{2}}$}} & \multirow{2}{*}{\multicolumn{5}{|c|}{$\frac{2 \pi 1^{\prime \prime}}{92 \pi \sigma^{\circ}}$}} & \multirow{2}{*}{\multicolumn{3}{|c|}{$\frac{3.510^{4}}{3911^{\prime}}$}} & 1100 & 20005 \\
\hline Pu & \multirow{3}{*}{\multicolumn{5}{|c|}{$57=05$}} & & & & & & & & & 2743 & 4005 \\
\hline $\mathrm{r}$ & & & & & & \multirow{2}{*}{\multicolumn{5}{|c|}{$6460^{\circ}$}} & \multicolumn{3}{|c|}{$1.600^{\circ}$} & 3502 & 2016 \\
\hline si & & & & & & \multirow{2}{*}{\multicolumn{5}{|c|}{ 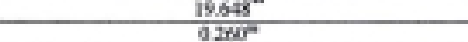 }} & \multirow{2}{*}{\multicolumn{3}{|c|}{$\frac{57019^{4}}{077 x^{2}}$}} & 3113 & $490 x$ \\
\hline PenV & \multicolumn{5}{|c|}{$\frac{101.5 \mathrm{~N}^{\prime \prime}}{0.5 \times 1^{4}}$} & & & & & & & & & 2743 & $40 \mathrm{cos}$ \\
\hline Fansa & \multirow{2}{*}{\multicolumn{5}{|c|}{$\frac{0.777^{4}}{429^{\prime}}$}} & \multicolumn{5}{|c|}{$03 \times$} & \multicolumn{3}{|c|}{$0,4=$} & 2232 & 3074 \\
\hline Viss & & & & & & \multirow{2}{*}{\multicolumn{5}{|c|}{$\frac{0312^{*}}{1003^{*}}$}} & \multirow{2}{*}{\multicolumn{3}{|c|}{$\frac{0.025^{5}}{0.5 \% 5}$}} & 3.1. & 49.8 \\
\hline Perviviss & \multicolumn{5}{|c|}{$0.478^{=}$} & & & & & & & & & 2212 & 3074 \\
\hline$C V(S)$ & \multicolumn{5}{|c|}{11.02} & \multicolumn{5}{|c|}{1234} & & & 1014 & & \\
\hline
\end{tabular}

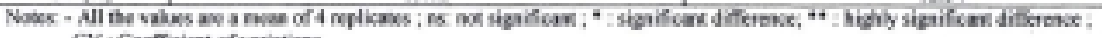

CV: Coeffichere of watiation 
Table 4. Percentage N-derived from fertilizer (\% N-Pu) and percentage $\mathrm{N}$-derived from soil (\% N-S) of straw, grain, and plants of lowland rice with several $\mathrm{N}$-fertilizer levels at three consecutive seasons.

\begin{tabular}{|c|c|c|c|c|c|c|c|c|c|c|c|c|c|c|c|c|c|c|c|c|}
\hline & \multicolumn{10}{|c|}{ Straw (S1) } & \multicolumn{10}{|c|}{ Grin (O) } \\
\hline & \multicolumn{5}{|c|}{$\begin{array}{l}\text { Percenage N-derived frum fertiliner } \\
\left(\% \mathrm{~N}-\mathrm{P}_{\mathrm{e}}\right)\end{array}$} & \multicolumn{5}{|c|}{$\begin{array}{l}\text { Perenties N-derived from soilt } \\
\qquad(\% \mathrm{~N}-\mathrm{S})\end{array}$} & \multicolumn{5}{|c|}{$\begin{array}{l}\text { Pereertiage N-derived fout fertilixer } \\
(\%, \mathrm{~N}-\mathrm{Pu})\end{array}$} & \multicolumn{5}{|c|}{$\begin{array}{l}\text { Percentuge N-derived from soilr } \\
\text { (AS }-5)\end{array}$} \\
\hline & N-PVI & ST-M2 & $\mathrm{m}=\mathrm{n}$ & W.roth & & N.n-1 & Nona & Nows & N-med & & Nend & Nhe & Nows & Narat & & S.Mal & Nond & Nons & N.Fed & \\
\hline nartaxisen & & & & & & & & & & & & & & & & & & & & \\
\hline V1 51 & 1728 & $22 n$ & 1091 & 30 & & $8 . x$ & $77 x$ & 5009 & 2549 & & 21.18 & 2111 & 17.5 & 1907? & & $7 \times 0$ & $7 \times 5$ & 1240 & 81.10 & \\
\hline & 1758 & 1545 & 391 & 28 & & 8.48 & 8435 & 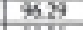 & $9[5]$ & & 1814 & 1689 & 39 & 131 & & 8106 & R.4 & लाक & $\underline{c 2 \pi}$ & \\
\hline & 765 & $8 \mathrm{~ns}$ & 446 & 64 & & Q.40 & 9133 & 95.9 & 9325 & & 964 & 1104 & 489 & 381 & & 603 & 105? & S1I & 9.19 & \\
\hline 83.81 & 18618 & 2265 & 1542 & 19.45 & & 8131 & 76.55 & 8158 & 8103 & & 22,21 & 2160 & 1632 & 17.45 & & $76 \times$ & 837 & 836 & 2551 & \\
\hline 82 & 1583 & 1991 & 5,62 & 565 & & 3017 & 81,00 & 9438 & 94.4 & & 13.76 & 1344 & 3.11) & 9.8 & & हल2 & 500 & 9180 & क्2 & \\
\hline 503 & 872 & 73 & 475 & 5,54 & & ติs & क्वि & 9225 & $94+5$ & & 297 & 8.45 & 627 & 937 & & प्रo4s & 91.52 & 9373 & भल & \\
\hline Borts & 1428 & 1613 & 8.14 & 1193 & & 5.73 & $5 \overline{6}$ & 91.51 & SIS 4 & & $15 \overline{2}$ & 15.17 & 350 & 1041 & & 80.08 & B5x) & 5014 & 890 & \\
\hline & & & & & & & & & & & & & & & & & & & & \\
\hline Bophay & & & & & $\frac{30-\gamma}{10}$ & & & & & Dov & & & & & $n_{0}-\mathrm{V}$ & & & & & $\frac{30-8}{8501}$ \\
\hline & 1415 & 1564 & 630 & 1218 & 127 & IIII & 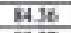 & कos. & 5797 & 87.72 & 1633 & 4917 & 397 & 1005 & in & 80.67 & B.15 & 903 & $50 \mathrm{x}$ & 8583 \\
\hline $\mathrm{V}_{2}$ & 144 & 16003 & 9.03 & 1022 & 12 프 & 1599 & 517 & 9097 & SonI & 0981 & 1591 & 1417 & $10 \times 4$ & 10.57 & 1292 & 850 & Exक्) & 8976 & 390 & 0048 \\
\hline Bathes & & & & & $8 \operatorname{sen} 5 x$ & & & & & Reses & & & & & $R=5 x$ & & & & & $\mathrm{pmss}$ \\
\hline \$1 & 17,97 & 2323 & 1516 & 2173 & 198 & 8703 & $8 \% 7$ & मक्ष & $7 \times 30$ & 800 & 2219 & 388 & 1709 & 1819 & 1996 & 77.5 & 7.13 & 3025 & 81.80 & 3045 \\
\hline 52 & IE: & 174 & 467 & 672 & 113 & 8032 & 3282 & 3534 & 9.16 & 82.6 & $15+5$ & 1515 & 104 & $7 a 5$ & 706 & 100 & घ्रज़ & 9225 & 5.66 & 5861 \\
\hline 503 & 818 & 10 & 461 & 611 & 6.73 & 91.84 & 920 & क्र52 & 928 & 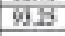 & $9 \in \mathbb{s}$ & 948 & 338 & 39 & 530 & का 31 & 900 & 942 & W.4. & 9243 \\
\hline & & & & & & & & & & & & & & & & & & & & \\
\hline $50-\sqrt{x=5}$ & $5 \times 1$ & 52 & $5 \times 3$ & & & S1 & 82 & 313 & & & का & 58 & 31 & & & 501 & $\Phi 2$ & $5 \mathrm{~s}$ & & \\
\hline vI & $18 \pi 5$ & 1113 & 688 & & & 31.5 & $8 \mathrm{Bn}$ & 9201 & & & 1911 & 1200 & 2.92 & & & $\sin 20$ & 525 & क्र2X & & \\
\hline$\sqrt{2}$ & $n=0$ & 1131 & 638 & & & $x+2$ & 3150 & 91.42 & & & 154. & $10,0,4$ & 7.42 & & & 800 & 8072 & cos & & \\
\hline \multicolumn{21}{|l|}{ A SONA } \\
\hline ANose & \multirow{2}{*}{\multicolumn{5}{|c|}{$\frac{5 \times 5 \cdot 7}{2125}$}} & \multirow{2}{*}{\multicolumn{5}{|c|}{ 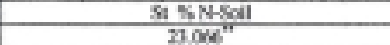 }} & \multirow{2}{*}{\multicolumn{5}{|c|}{$\frac{a 5 k-\sqrt{2}}{17.250^{2}}$}} & \multirow{2}{*}{\multicolumn{5}{|c|}{ os seseg }} \\
\hline Treatrons & & & & & & & & & & & & & & & & & & & & \\
\hline N & \multirow{2}{*}{\multicolumn{5}{|c|}{$\frac{15.55}{0.97785}$}} & \multirow{2}{*}{\multicolumn{5}{|c|}{$\frac{31414^{\prime \prime}}{678 \%}$}} & \multicolumn{5}{|c|}{$21755^{2}$} & \multicolumn{5}{|c|}{$52 \mathrm{~N}^{\prime \prime}$} \\
\hline $\mathrm{v}$ & \multirow{2}{*}{\multicolumn{5}{|c|}{$163 \times 1 y^{\prime \prime}$}} & & & & & & \multirow{2}{*}{\multicolumn{5}{|c|}{$\frac{13 m^{\prime \prime}}{14097^{\prime \prime}}$}} & \multirow{2}{*}{\multicolumn{5}{|c|}{$\frac{1.10^{2}}{1.97 \pi^{4}}$}} \\
\hline St & & & & & & \multicolumn{5}{|c|}{ किजाए } & & & & & & & & & & \\
\hline mav & \multirow{2}{*}{\multicolumn{5}{|c|}{4006}} & \multirow{2}{*}{\multicolumn{5}{|c|}{ 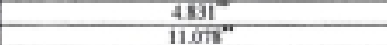 }} & \multirow{2}{*}{\multicolumn{5}{|c|}{$100 \mathrm{~g}^{\prime \prime}$}} & & & $609 z^{2}$ & & \\
\hline Phass & & & & & & & & & & & & & & & & & & $2165^{2}$ & & \\
\hline Ms & & & $2000^{\circ}$ & & & & & $0 \sqrt{5} s^{2}$ & & & & & $0310^{\circ}$ & & & & & $6317^{2}$ & & \\
\hline Pawiviss & & & $1.8 \mathrm{sg}^{2}$ & & & & & $2299^{-2}$ & & & & & $1.280^{2}$ & & & & & $13 \sigma^{2}$ & & \\
\hline cros & & & $227 \pi$ & & & & & 376 & & & & & 2221 & & & & & 929 & & \\
\hline
\end{tabular}




\section{N-Uptake Derived From Fertilizer (N-Pu) and N-Uptake Derived From Soil (N-soil)}

The data $\mathrm{N}$-uptake derived from fertilizer $(\mathrm{N}-\mathrm{Pu})$ and $\mathrm{N}$-uptake from soil (N-soil) are presented in Tables 5, 6 and 7. As for $\% \mathrm{~N}-\mathrm{Pu}$ and $\% \mathrm{~N}$-soil the N Pu uptake for St, G, P1 (Table 5) are far below N-soil (Table 6) for the same parameters. This could be due to that the N-soil available exceeded the $\mathrm{N}-\mathrm{Pu}$ so the plants could use more $\mathrm{N}$-soil compared to that of N-Pu. From Table 5, it is shown that significant differences were found for N-Pu in St, G, and P1. Here again it shown that the form of urea as tablets added with Azi and Azc (Pu1 and Pu2) are above that of urea as prill combined with Azi and Azc. As the form of urea as tablets is assumed to be more effective than prill due to its placement and release. The urea in form of tablets has to be put about $5 \mathrm{~cm}$ under the soil surface while when in the form prill the urea is put at the surface, so more open to volatilization and surface flow compare to that of urea in the form of tablets. This is supposed why N-Pu uptake of Pul and $\mathrm{Pu} 2$ are higher than that of Pu3, Pu4 for St, G and P1.

Table 5. N-Pu and N-soil uptake of straw of lowland rice applied with several levels of $\mathrm{N}$-fertilizers at three consecutive seasons.

\begin{tabular}{|c|c|c|c|c|c|c|c|c|c|c|}
\hline & \multicolumn{5}{|c|}{ 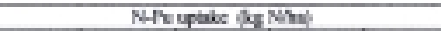 } & \multicolumn{5}{|c|}{ 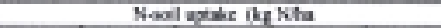 } \\
\hline & Nक्त & Nan: & N.t. & NFod & & NhI & NWE & NAw & Shat & \\
\hline \multicolumn{11}{|l|}{ Rophaswiss } \\
\hline VI Sal & 322 & 432 & 247 & 5,08 & & 19.73 & 14.67 & $1 \times 73$ & 1525 & \\
\hline$\$ \mathbf{2}$ & 479 & $3 . \pi$ & 085 & $1.9 \pi$ & & 2ISक & 2056 & 225 & 2525 & \\
\hline क्षात & गै & 235 & 136 & 210 & & 2860 & कod & $3 \times 4$ & 2564 & \\
\hline $\mathrm{V} 2 \mathrm{sal}$ & 435 & 8.06 & 424 & 4.40 & & 19.11 & $10 . \pi$ & 17.04 & 110 & \\
\hline $\mathbf{5 2}$ & 993 & 6.43 & 1806 & 1.95 & & 2591 & 235 & 3131 & 31.25 & \\
\hline काज & 34 & 210 & $\ln$ & 215 & & 353 & इसा & अक & $35 \mathrm{k}:$ & \\
\hline Bath & 406 & $4+4$ & 2.11 & 208 & & 21.77 & 24.9 & 250 & 25.70 & \\
\hline Enater & & & & & $\sin v$ & & & \multirow{2}{*}{2420} & & 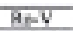 \\
\hline vI & 395 & $31 \mathrm{BS}$ & $|\Delta|$ & 286 & 228 & 23.45 & 213 & & 2251 & 2366 \\
\hline $\mathrm{V} 2$ & 4.49 & 3.17 & 201 & 3.77 & 377 & 2805 & 2801 & 27.51 & $25 \times 7$ & 28.17 \\
\hline Dinturess & & & & & keses & & & & & 2058 \\
\hline sil & $3.7 \pi$ & 5.16 & 356 & 477 & 4.27 & 17.46 & 172 & 1818 & 17.42 & 17.97 \\
\hline$\$ 2$ & 9.17 & 3.11 & 157 & 1.95 & 34 & 2क्त & 2204 & 21.57 & 27.44 & 2595 \\
\hline 81 & 36 & 296 & $\mid \mathrm{Ba}$ & 218 & 24 & 916 & भâ & มี1? & 2251 & 1753 \\
\hline Bovah & 5.1 & 50 & हs & & & 35 & 50 & \multirow{2}{*}{ si } & & \\
\hline \multirow{2}{*}{$\frac{v 1}{12}$} & 3.76 & 224 & $2 \times 0$ & & & 1627 & 2204 & & & \\
\hline & 4.78 & 3.96 & 250 & & & 1857 & 200 & \multicolumn{2}{|l|}{360} & \\
\hline \multirow{2}{*}{\multicolumn{11}{|c|}{ ANowA }} \\
\hline & & & & & & & & & & \\
\hline & & & Actomph & & & & Brined & & For & \\
\hline & & & & & & & & & 35 & 15 \\
\hline tnelestb & & & 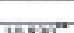 & & & & GE:" & & 1655 & 3 लूक \\
\hline p & & & $36251^{\prime \prime}$ & & & & 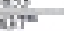 & & mis & $\frac{2103}{1685}$ \\
\hline $\mathrm{y}$ & & & $1815^{2}$ & & & & $539^{\prime \prime}$ & & 152 & 900 \\
\hline 5 & & & $310 \pi^{2}$ & & & & $1.29^{2}$ & & 1.133 & 4525 \\
\hline $\mathrm{hes}$ & & & By" & & & & $y=$ & & Tat & 405 \\
\hline Mas: & & & $15.973^{\circ}$ & & & & $\mathrm{sed}^{=}$ & & 2132 & 364 \\
\hline$\sqrt{755}$ & & & $1 \mathrm{Nr}$ & & & & $\pi]^{2}$ & & 1.13 & 4925 \\
\hline Kmovas & & & $1.4 \overline{2}^{\prime \prime}$ & & & & $\mathrm{N}^{2}$ & & 1292 & ग्रूप \\
\hline CV $\%$ & & & 2753 & & & & 375 & & & \\
\hline
\end{tabular}


Table 6. N-Pu and N-soil uptake of grain of lowland rice applied with several levels of $\mathrm{N}$-fertilizers at three consecutive seasons.

\begin{tabular}{|c|c|c|c|c|c|c|c|c|c|c|}
\hline & \multicolumn{5}{|c|}{ 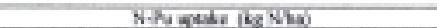 } & \multicolumn{5}{|c|}{ 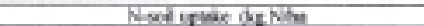 } \\
\hline & Nhn: & N-12 & $\mathrm{N}-\mathrm{TS}$ & Nhet & & N-Fal & $\mathrm{N} \cdot \mathrm{M} 2$ & 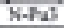 & What & \\
\hline \multicolumn{11}{|l|}{ Wohanks } \\
\hline vI sal & 1315 & 13.15 & 1645 & 1131 & & A12s & WE: & 455 & क्रका & \\
\hline 802 & 1499 & 1155 & $4 \$$ & 500 & & 55.41 & $35 \mathrm{s2}$ & 52as & MIS & \\
\hline रकी & 25 & $32 x$ & 35 & dat & & 6 का & तथा & $6 \sqrt{62}$ & 7225 & \\
\hline $\mathrm{V} 2 \mathrm{sal}$ & 13.41 & 1215 & 107 & 116 & & $4 \leqslant 52$ & 45 & $(50)$ & Siats & \\
\hline $8 \times 2$ & $9+4$ & $9 \times 1$ & 457 & 5.24 & & $9 s$ & SL.so & $95 \%$ & $52 \pi$ & \\
\hline nis & 205 & 618 & $4 \pi$ & की & & 653 & हकन & 620 & 6375 & \\
\hline Wathe & 10.73 & 10.11 & das & 874 & & 3152 & $31 \mathrm{~m}$ & 5228 & स196 & \\
\hline Rathav & & & & & $B \in V$ & & & \multirow{2}{*}{ wh } & & Mang \\
\hline $\mathrm{v} 1$ & 11.64 & 11.11 & 812 & $2 x$ & 58 & 95.45 & Sals & & 624 & BE \\
\hline vi & $9+5$ & 95 & 548 & 600 & 742 & $92 \pi$ & 95.45 & 5458 & Fio4 & 9732 \\
\hline Po-fres & & & & & $2+-5$ & & & & & Bम्यू \\
\hline का & 1935 & 1265 & 93 & III & $11 \mathrm{ts}$ & 4763 & 4735 & 45.75 & soss & 4530 \\
\hline $\sin 2$ & 1260 & 167 & 477 & 512 & $x+3$ & 619 & सIS & 628 & 6205 & 620 \\
\hline 50 & 7.4 & 7.30 & 3.74 & 40 & 5.50 & es.s & $51+2$ & 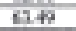 & 6113 & sas \\
\hline & & & & & & & & \multirow[b]{2}{*}{85} & & \\
\hline Dovesi & Sal & $5 \sin$ & 503 & & & si & 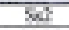 & & & \\
\hline 81 & 12.10 & 975 & 5.75 & & & 4330 & 84.4 & MN & & \\
\hline$n$ & 115 & 255 & 325 & & & $4 y$ & क्ज4 & बलि & & \\
\hline \multirow{2}{*}{\multicolumn{11}{|c|}{ Wrova }} \\
\hline & & & & & & & & & & \\
\hline & \multirow{2}{*}{\multicolumn{5}{|c|}{ Peclatiasd }} & \multirow{2}{*}{\multicolumn{2}{|c|}{ F-Colschavd }} & \multicolumn{3}{|c|}{ Exaby } \\
\hline & & & & & & & & & 55 & Is \\
\hline Treancti: & \multicolumn{5}{|c|}{$12.43 \mathrm{~K}^{2}$} & \multicolumn{3}{|c|}{$5041^{\prime \prime}$} & $\mathrm{set}$ & $20 \mathrm{~m}$ \\
\hline $\mathrm{h}$ & \multirow{2}{*}{\multicolumn{5}{|c|}{$\frac{3.197}{624^{\prime \prime}}$}} & \multicolumn{3}{|c|}{$2655^{2}$} & 278 & $40 \mathrm{sg}$ \\
\hline$\gamma$ & & & & & & & Ais & & करा? & 7016 \\
\hline \$n & \multicolumn{5}{|c|}{7.143} & & $6 \bar{g}^{\prime \prime}$ & & 15 & Coss \\
\hline Fon & & & $105=$ & & & & $55^{-1}$ & & 2748 & 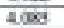 \\
\hline Phass & & & $231^{\prime}$ & & & & $30^{\circ}$ & & 52 & $30 \mathrm{~m}$ \\
\hline W5t & & & 6.57 & & & & $312^{\prime \prime}$ & & III & 405 \\
\hline Fowiven & & & isyra & & & & 407 & & 2232 & $3 \pi 74$ \\
\hline ल्V हु & & & 24.13 & & & & 1009 & & & \\
\hline
\end{tabular}

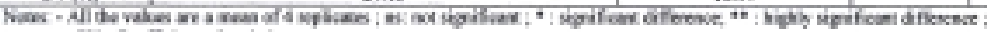

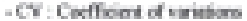


Table 7. N-Pu and N-soil uptake of plants (straw + grain) of lowland rice applied with several levels of $\mathrm{N}$-fertilizers at three consecutive seasons.

\begin{tabular}{|c|c|c|c|c|c|c|c|c|c|c|}
\hline & \multicolumn{5}{|c|}{ 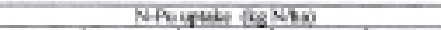 } & \multicolumn{5}{|c|}{ 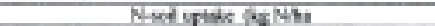 } \\
\hline & NAl & What & $\mathrm{N}-\mathrm{m}$-3 & NDA & & Whal & $\mathrm{N}-\mathrm{m} 2$ & N.P. & $\mathrm{kin}$ & \\
\hline \multicolumn{11}{|l|}{ An-Paves: } \\
\hline V1 81 & Thet & IDat & 7242 & 1656 & & $64 \infty 6$ & क्या & 6925 & $66 \times 5$ & \\
\hline $\mathrm{m}_{2}$ & 1806 & $|65|$ & 29 & 725 & & क्रा20 & या? & 24 & 813 & \\
\hline Sas & 352 & 8.94 & 4.50 & 810 & & 204 & 10035 & 3585 & Dons: & \\
\hline प: 51 & हाज़ & 21.90 & 17.21 & 1108 & & 780 & MS & 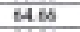 & 6028 & \\
\hline $\sin 2$ & 143 & $\mid 521$ & 721 & 205 & & Sका & $5=5$ & BhP & 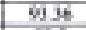 & \\
\hline Sas & 325 & 100 & 600 & 5.55 & & 10015 & 16076 & (7) 15 & कo.s. & \\
\hline Both & 14.86 & $14 \times$ & 8.98 & 1011 & & S.18 & 3.4 & 400 & 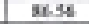 & \\
\hline Bothay & & & & & $\cos$ & & & & & bov \\
\hline $\mathrm{v} 1$ & 14.53 & 145 & 7.71 & 1000 & 11.72 & s. 0 & 11.56 & 15.15 & 2365 & $\operatorname{lis} 7$ \\
\hline$\sqrt{2}$ & 13.15 & 12क & DलA & 1021 & 1260 & sos & 5.55 & 255 & 800 & 5.95 \\
\hline Be-7ass & & & & & Reres & & & \multirow{2}{*}{ 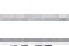 } & & 605 \\
\hline 501 & 1922 & 1255 & 7104 & 1723 & 17.78 & 8278 & जास & & es.00 & 20.49 \\
\hline 8 & 1623 & 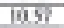 & 634 & 7.79 & 11.41 & 57.28 & 510 & BE: & 9124 & STP \\
\hline$\times 3$ & 9.14 & 314 & 365 & 502 & 335 & $16 \times 3$ & 100 & $56+1$ & 120 & 100 \\
\hline & & & & & & & & \multirow[b]{2}{*}{583} & & \\
\hline $20 \sqrt{2}$ & $5 \times 1$ & 50 & 85 & & & 51 & 50. & & & \\
\hline$n$ & $15 \mathrm{~s}$ & 11.15 & 7.6 & & & 8557 & 3588 & दूर & & \\
\hline$\sqrt{2}$ & 10.20 & $60 \%$ & 723 & & & 57.41 & Sals & 101.27 & & \\
\hline & & & & & & & & & & \\
\hline \multicolumn{11}{|l|}{ ANONA } \\
\hline & \multicolumn{5}{|c|}{ Pedented } & \multirow{2}{*}{\multicolumn{2}{|c|}{ F-Cuksulaied }} & \multicolumn{3}{|c|}{ T-Twk } \\
\hline & & & & & & & & & 58 & $1 \%$ \\
\hline Tratrwasts & \multicolumn{5}{|c|}{$23.47^{\circ}$} & \multicolumn{2}{|c|}{$102 \sigma^{\prime \prime}$} & \multicolumn{2}{|c|}{ IISS } & 1006 \\
\hline Wh & & & $435 \mathrm{Nm}$ & & & & $55^{2}$ & & 2.743 & 4063 \\
\hline $\mathrm{r}$ & & & $3.7 \pi^{\circ}$ & & & & $\omega^{2}=$ & & 162 & 7016 \\
\hline 5 & & & 16754 & & & & $1573^{\circ}$ & & 1.133 & 4008 \\
\hline N.tav & & & $1.244^{2}$ & & & & $\mathrm{SW}^{2}$ & & 2.743 & 408 \\
\hline Noneri & & & $6>71^{2}$ & & & & $500^{6}$ & & 2232 & 3.074 \\
\hline Vost & & & $904^{\prime \prime}$ & & & & arर" & & 2109 & 495 \\
\hline Pavives & & & $1.274^{-1}$ & & & & $51 x^{2}$ & & 2312 & 3004 \\
\hline crisl & & & 1885 & & & & 157 & & & \\
\hline
\end{tabular}

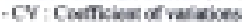

Differences were found between $\mathrm{V} 1$ and V2, for St $(* *), \mathrm{G}(* *)$, $\mathrm{P} 1$ (*). N-Pu for St: $\mathrm{Vl}<\mathrm{V} 2, \mathrm{G}: \mathrm{Vl}>\mathrm{V} 2, \mathrm{P} 1: \mathrm{Vl}<\mathrm{V} 2$. Obviously in St V2 could distributed less $\mathrm{N}-\mathrm{Pu}$ to the grains $(\mathrm{G})$, resulting in higher $\mathrm{N}-\mathrm{Pu}$ of $\mathrm{V} 1$ than V2. While for P1 due to its accumulation of St + G. Apparently the $\mathrm{N}-\mathrm{Pu}$ of $\mathrm{St}$ in $\mathrm{V} 2$ influence more the N-Pu of P1 compared to that of V1. The most important part is $\mathrm{G}$ for lowland rice, so with $\mathrm{V} 1$ having more $\mathrm{N}-\mathrm{Pu}$ than $\mathrm{V} 2$, then this will be an important issue to choose V1 above V2 besides its dry weight to be planted in the field. This also showed that V1 is superior to V2 in efficiently distributed N-Pu from St to G. Contrary to the N-to uptake, the $\mathrm{N}-\mathrm{Pu}$ uptake decrease with the passing of seasons (Table 4), where Ss1>Ss2>Ss3 for St, G, P1. This meant that that the constituent of the N-to which is $\mathrm{N}$-soil + N-Pu increase, it reaches the highest level by the increase of $\mathrm{N}$-soil as will be shown in the increase of $\mathrm{N}$-soil uptake which be discussed in the $\mathrm{N}$-soil uptake. The interaction between $\mathrm{Pu} x \mathrm{~V}$ only shows $\mathrm{G}$ where $\mathrm{N}-\mathrm{Pu} \mathrm{V1}>\mathrm{N}-\mathrm{Pu} \mathrm{V} 2$, while for St and $\mathrm{P} 1$ the reverse occurred. As mentioned before for lowland rice, the most important product is grain 
(G). So that the highest dry weight, the highest $\mathrm{N}$ uptake whether from $\mathrm{Pu}$ or soil is the reason to be taken into consideration to choose V1 above V2. Interaction between $\mathrm{Pu} \times \mathrm{Ss}$ with the progress of seasons showed that the $\mathrm{N}-\mathrm{Pu}$ is decreasing. An other important observation as in $\mathrm{Pu} x \mathrm{~V}$, here for $\mathrm{Pu} \times \mathrm{Ss}$ too the form of urea in tablets is superior to that of prill, added with Azi or Azc. This is all true for St, G and P1. The important interaction data of $\mathrm{Pu} \times \mathrm{V} \times \mathrm{S}$ are that with the passing of seasons (Ss) the N-Pu decreased for $\mathrm{V} 1$ and V2, and for V1 and V2 the N-Pu in form of tablets is superior to $\mathrm{N}-\mathrm{Pu}$ in form of prill.

For the treatments for St, G, P1 showed all highly significant difference in $\mathrm{N}$-soil uptake. Breaking the treatments to single and interaction treatments show data as will be forwarded next. No significant difference was shown by application of $\mathrm{Pu}$ on $\mathrm{N}$-soil uptake $\left(\mathrm{Pu}^{\text {ns }}\right)$. But highly significant difference for $\mathrm{V}$ and Ss. For V, again as in N-Pu uptake, here it shown again that for G the N-soil uptake for G V1 > V2 and for both St and Pu the reverse occurred. Contrary to $\mathrm{N}-\mathrm{Pu}$, with progress of time (Ss) the N-soil increased. This meant that $\mathrm{N}$-soil with the passing of seasons (Ss), accumulated to high amounts and this N-soil provided the largest $\mathrm{N}$ part uptake of St, G, P1. Could this be a sign that the SOM has accumulated and this would be a reason on the increase of soil quality from the view point of $\mathrm{N}$. Due to these data it is correct to say that for good end production of lowland rice which is grain the main role is done by $\mathrm{N}$-soil. This need more investigation.

For the interaction of $\mathrm{Pu} \times \mathrm{V}, \mathrm{Pu} \times \mathrm{Ss}, \mathrm{V} \times \mathrm{Ss}$ and $\mathrm{Pux} \mathrm{V} \times \mathrm{Ss}$ no significant differences were found, except for V x Ss only for St. As has been mentioned before this obviously due to the distribution of $\mathrm{N}$ from St to G, where for V2 the distribution from St to G was less than that of Vl.

The most important about $\mathrm{N}$-soil uptake is that the addition of $\mathrm{N}-\mathrm{Pu}$ combined with Azi and Azc whether in the form of tablets or prills has no influence on N-soil uptake. Further with the passing of seasons showed $\mathrm{N}$-soil accumulated while for $\mathrm{N}-\mathrm{Pu}$ it decreased significantly. This is valid for St, G, P1.

\section{CONCLUSIONS}

From this work apparently N-Pu play a less important role in growth of lowland crop expressed in several parameters compared to $\mathrm{N}$-soil. The form of $\mathrm{N}$-urea in tablets are superior to that the form of urea in prills.

For the last product of lowland rice which is grain obviously V1 (Atomita-1) is better than V2 (IR-64) expressed in t/ha.

The progress of seasons showed clearly that there is an $\mathrm{N}$ accumulation which might be the increase of soil organic matter (SOM) and that means there is an increase in soil quality in the view point of $\mathrm{N}$. 


\section{REFERENCES}

1. RAP A - FAO. Summary of Recommendation and Conclusions. In : Report of the Experts Consultation of the Asian Network on problem Soils, Bangkok 25 - 29 Oct 1993, 16-21 (1993).

2. ARSJAD, S., Konservasi Tanah dan Air, Penerbit IPB, Bogor (1989).

3. OLDEMAN, L.R., An International Methodology for an Assessment of Soil Degradation Land Georeferenced Soil and Terrain Data Base. In : Report of the Experts Consultation of the Asian Network on problem Soils, Bangkok 25 - 29 October 1993, 35 - 60 (1993).

4. VERSTRAETTE, W., Soil Microbiology Ecology, State University of Ghent (1989).

5. STEVENSON, F. J., Humus Chemistry. Genesis, Composition, Reaction. $2^{\text {nd }}$ Ed. John Willey and Sons, New York. 